\title{
Estudo das propriedades mecânicas de pavers de concreto obtidos através da introdução de resíduos plásticos industriais
}

\author{
Study of mechanical properties of concrete pavers obtained through the \\ introduction of industrial plastic residues
}

\author{
Aguinaldo Lenine Alves' \\ Antonio Aparecido Zanfolim² \\ Fernanda Gabriele Nascimento Gotardi ${ }^{3}(*)$ \\ Renata de Mauro Torres ${ }^{4}$ \\ Greicieli de Lima Zandoná Godoy ${ }^{5}$
}

\section{Resumo}

O descarte inadequado de resíduos sólidos prejudica o meio ambiente e, em vista da grande produção de resíduos plásticos laminados na indústria de embalagens flexíveis e a crescente demanda por novas tecnologias no setor da Construção Civil, o presente trabalho buscou inserir resinas plásticas na argamassa de concreto para confecção de pavers (lajotas) utilizados para calçamento. O resíduo plástico foi introduzido em substituição à areia, nas proporções de 5\% e 15\% para posterior comparação com corpos de prova sem substituição. Propriedades físicas como granulometria resistência mecânica a compressão, absorção de água, índice de vazios e massa específica da amostra seca e saturada foram consideradas para verificar a viabilidade e aplicação deste novo material. Como resultado, pôde-se observar que as adições dos resíduos melhoraram a resistência mecânica para ambas as substituições e proporcionou, também, redução do índice de vazios das amostras de 5\%, o que reduz a absorção de água e aumenta a durabilidade do material. As amostras de $15 \%$ apresentaram pequeno aumento na absorção de água, o qual não implicou redução da sua resistência, se comparado aos pavers de referência.

Palavras chaves: reciclagem; construção civil; resíduos plásticos.

1 Dr.; Ciência dos Materiais; Universidade Estadual Paulista Júlio de Mesquita Filho, UNESP, Brasil; Professor/pesquisador ligado ao CEPEMAT - Centro de Pesquisa em Materiais da Universidade Estadual de Mato Grosso do Sul, UEMS; Endereço: Cidade Universitária de Dourados - Rodovia Itahum, Km 12, s/n - Jardim Aeroporto, CEP: 79804-970, Dourados, Mato Grosso do Sul, Brasil: E-mail: lenine@uems.br

2 Dr.; Ciência e Tecnologia de Materiais; Professor/pesquisador ligado ao CEPEMAT - Centro de Pesquisa em Materiais da Universidade Estadual de Mato Grosso do Sul, UEMS; Endereço: Cidade Universitária de Dourados - Rodovia Itahum, Km 12, s/n - Jardim Aeroporto, CEP: 79804-970, Dourados, Mato Grosso do Sul, Brasil: E-mail: zanfolim@ uems.br

3 Engenheira Ambiental pela Universidade Estadual de Mato Grosso do Sul, UEMS, Centro de Pesquisa em Materiais, CEPEMAT; Endereço: Cidade Universitária de Dourados - Rodovia Itahum, Km 12, s/n - Jardim Aeroporto, CEP: 79804-970, Dourados, Mato Grosso do Sul, Brasil: E-mail: fernanda.gotardi@gmail.com (*) Autor para correspondência

4 Engenheira Ambiental pela Universidade Estadual de Mato Grosso do Sul, UEMS, Centro de Pesquisa em Materiais, CEPEMAT; Endereço: Cidade Universitária de Dourados - Rodovia Itahum, Km 12, s/n - Jardim Aeroporto, CEP: 79804-970, Dourados, Mato Grosso do Sul, Brasil: E-mail: renatatores30@gmail.com

5 Ms.; Química; Técnico de Laboratório da Universidade Estadual de Mato Grosso do Sul, UEMS, Centro de Pesquisa em Materiais, CEPEMAT; Endereço: Cidade Universitária de Dourados - Rodovia Itahum, Km 12, s/n - Jardim Aeroporto, CEP: 79804-970, Dourados, Mato Grosso do Sul, Brasil: E-mail: greici@uems.br

\begin{tabular}{llllll}
\hline Ambiência & Guarapuava (PR) & v.l5 n.l & p.73 - 93 & Jan/Abr 2019 & ISSN I808 - 025I
\end{tabular}




\section{Abstract}

The improper disposal of plastic waste damages the environment and, in view of the large production of plastic waste in the flexible packaging industry and the growing demand for new technologies in Construction Sector, the present study sought to insert plastic resins in concrete for producing pavers (tile) used for sidewalks. The plastic waste was introduced to replace the sand in proportions of $5 \%$ and $15 \%$ to be compared with control specimens. Mechanical properties such as compressive strength, water absorption, porosity, density of the dry and saturated sample were considered to verify the feasibility and application of this new material. As a result, it can be observed that the additions of waste improved mechanical resistance for both substitutions and also provided a reduction of the porosity of the samples of $5 \%$, which reduces the water absorption and increases the durability of the material. Samples of $15 \%$ showed a small increase in water absorption, which did not cause a reduction of its strenght compared to the control pavers.

Key words: recycling; construction; plastic waste.

\section{Introdução}

O desenvolvimento industrial e a crescente demanda por novas tecnologias, aliados à problemática ambiental, trazem uma série de preocupações para o setor fabril, o qual passa a buscar novas alternativas para a reutilização dos seus resíduos. Neste contexto, a indústria plástica surge como uma alternativa de sustentabilidade, já que o resíduo da sua principal matéria prima, o plástico, por apresentar bom desempenho a um menor custo, pode ser utilizado em substituição a vários outros materiais como, por exemplo, ao uso do aço, do vidro e do metal (PIATTI, 2005).

O plástico (do grego plásticos: próprio para ser moldado ou modelado) é o termo geral dado a materiais constituídos essencialmente de ligações moleculares orgânicas, que resultam de síntese ou transformação de produtos naturais, formando macromoléculas conhecidas como polímeros que podem ser moldados por ação de calor e/ou pressão (CANGEMI, 2005; CÂNDIDO, 2009). Quanto a sua capacidade de reciclagem, pode ser classificado em dois grandes grupos: os termoplásticos, que podem ser moldados diversas vezes sem perdas significativas em suas propriedades e os termofixos que, uma vez moldados, não podem ser fundidos e remodelados (OLIVEIRA, 2012).

A Resolução n 313/2002, do Conselho Nacional do Meio Ambiente - CONAMA define como "resíduos nos estados sólido e semissólido, todo material resultante de atividades da comunidade de origem: industrial, doméstica, hospitalar, comercial, agrícola, de serviços e de varrição cujas particularidades tornem inviável seu reaproveitamento através de soluções técnicas". Dentro desta categoria, encontram-se os resíduos plásticos (BRASIL, 2002).

Os plásticos, mesmo quando destinados a aterros controlados, podem levar séculos para sua completa decomposição. Trata-se de um material que tem chamado a atenção da comunidade, pela enorme quantidade de descarte pós-consumo e pelos impactos ambientais causados por sua disposição incorreta, o que pode ocasionar danos à saúde dos seres humanos e dos animais, principalmente por conta dos aditivos químicos utilizados na sua fabricação (OLIVEIRA, 2012). 
Paralelo a isto, está o setor da Construção Civil, que carece de uma grande quantidade de agregados naturais, pois, segundo PIETROBELLI (2010), apenas no Brasil, o consumo anual de areia e brita na produção de concreto e argamassa é de 220 milhões de toneladas e, em algumas cidades, esses recursos já estão se tornando escassos.

A aplicação de materiais poliméricos na construção civil está sendo bastante difundida, visto que o concreto, o material estrutural de maior aplicação, possui características como: facilidade de moldagem, resistência à compressão, durabilidade, porosidade e absorção de água, as quais podem ser melhoradas com adição de materiais reciclados (ROYER et al, 2005).

O concreto para fabricação de pavers (lajotas) comuns é composto de areia (agregado miúdo), brita (agregado graúdo), cimento portland e água. A pedra britada é obtida em uma pedreira, onde ocorre à desintegração, por explosão controlada da rocha que dá origem à brita. Esse material é levado ao britador e, posteriormente, ela passa por diversas peneiras de malhas diferentes onde são classificados de acordo com sua granulometria. No caso da areia, é um material largamente utilizado na construção civil, embora, no Brasil, a maior parte utilizada na construção civil seja extraída dos leitos de rios, é possível também extraí-la em areais ou portos de areia, depósitos lacustres, minas ou dunas, causando impactos ambientais (VIEIRA, 2015). A melhor maneira de diminuir a utilização desses recursos e conservar o meio ambiente é o emprego de materiais reciclados ou alternativos (ALWAELI, 2013). O cimento, principal responsável pela transformação dos componentes no produto final desejado, quando misturado com água e outros materiais de construção, pode resultar nos concretos e nas argamassas usadas na construção de casas, edifícios, pontes, etc. A principal característica deste componente é endurecer sob ação da água (ASSOCIAÇÃO BRASILEIRA DE CIMENTO PORTLAND, 2002).

Muitos estudos têm sido realizados na confecção de compósitos cimentícios empregando materiais recicláveis ou alternativos em substituição parcial da areia ou brita, apresentando potencial utilização na construção civil: a viabilidade técnica da utilização da fibra de coco na utilização em argamassas, além de concretos tijolos de alvenaria para vedação (SILVA et al, 2015; SILVA et al, 2018); compósitos cimentícios produzidos com resíduos da indústria madeireira (RIBEIRO e VASCONSELOS, 2018); viabilidade do emprego de cinza de casca de arroz natural em concreto estrutural (ISAIA et al, 2017); blocos para pavimentação e alvenaria como uma solução viável para o aproveitamento e destino dos resíduos da indústria cerâmica( SOUZA et al, 2018); de blocos de concreto com utilização de resíduos reciclados da própria fabricação dos blocos (GOMES et al, 2017); concreto com incorporação de lodo de estação de tratamento de água podendo ser utilizado com finalidades não estrutural (TAFAREL et al, 2016); tijolos ecológicos indicados para alvenaria de vedação com o uso de granulado de borracha em substituição parcial ao agregado miúdo (SILVA et al,2017); compósitos com resíduos de plástico, policloreto de vinila (PVC) e politereftalato de etileno (PET) têm sido apontado com potencial para utilização na construção civil ( MATTAR e VIANA, 2012; FERRARI, 2017; SOUZA et al, 2015).

A introdução de resíduos plásticos em pavers foi realizada em conformidade com a Lei n. 12.305, de 02 de agosto de 2010, que institui a Política Nacional de Resíduos Sólidos, à qual estão sujeitos os responsáveis diretos ou indiretos pela geração de resíduos sólidos (BRASIL, 2010). Inerente a isto, tem-se a redução no descarte de resíduos plásticos e a diminuição dos impactos ambientais resultantes da extração da areia. Desta forma, este estudo apresenta uma opção para 
o reaproveitamento dos resíduos plásticos oriundos da indústria de embalagens. A sugestão é aplicá-lo parcialmente ao concreto utilizado na fabricação de pavers, material empregado na pavimentação de áreas externas como calçamentos de parques, postos de combustíveis, pátios de manobra de cargas, estacionamentos, calçadas, residências, praças e, até mesmo, ruas e avenidas.

O principal objetivo deste estudo foi analisar o comportamento da resistência mecânica em pavers de concreto, incorporados com proporções adequadas de resíduos plásticos irrecuperáveis, provenientes das indústrias de embalagens da cidade de Dourados - MS. Foram conformados corpos de prova amostrais com substituição de 5 e 15\% em relação ao agregado miúdo, bem como conformadas amostras referências (sem substituição) para determinação do melhor traço. A fim de se reforçar a aplicabilidade dos pavers incorporados com resíduos plásticos, realizaram-se também análises de absorção de água, índice de vazios, massa específica da amostra seca e saturada.

\section{Materiais e Métodos}

Esta pesquisa foi baseada em experimentos laboratoriais realizados no Laboratório de Caracterização Mecânica de Materiais do Centro de Pesquisas em Materiais (CEPEMAT) da Universidade Estadual de Mato Grosso do Sul (UEMS/DOURADOS), com o intuito de conformar pavers de concreto com substituição parcial do agregado miúdo por resíduos plásticos.

\section{Obtenção dos materiais e tratamento dos resíduos plásticos}

O resíduo da confecção de sacolas plásticas, termoplásticos constituídos de polietileno de baixa densidade, foi coletado em uma indústria de embalagens de Dourados/MS, fundido, através de uma extrusora e transformado em pequenos pellets esféricos (Figura 1) com diâmetro aproximado de $5 \mathrm{~mm}$ (BEZERRA et al, 2016). Esse procedimento faz com que o material se torne mais denso, facilitando sua fixação no concreto. Os agregados naturais (brita e areia) e o cimento Portland foram obtidos junto a estabelecimentos comerciais.

\section{Figura 1: Pellets esféricos de resíduos de sacolas plásticas. Fonte: Autoria própria (2015).}

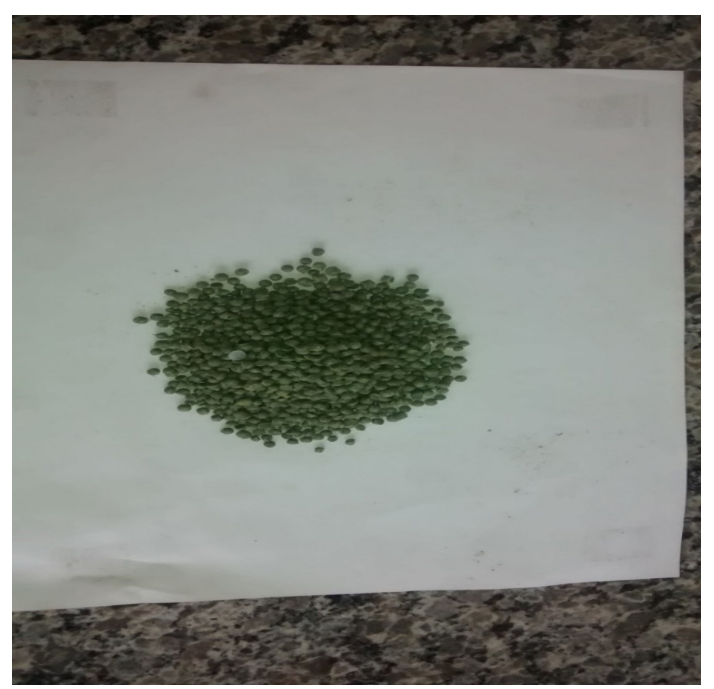




\section{Ensaio granulométrico dos resíduos plásticos}

Foram empregados como agregados naturais os utilizados tradicionalmente para produção de concretos, ou seja, areia e pedra brita (brita 0 ). Nesta fase foram realizados estudos regulados pela norma ABNT NBR NM 248/2003, que trata da determinação da composição granulométrica. Os grãos de resíduos plásticos, em forma de pellets esféricos, e os agregados naturais foram caracterizados através da balança semi-analítica (OHAUS/ARC120) e um agitador mecânico de peneiras (BERTEL) cujas malhas foram trocadas de acordo com o agregado em teste.

\section{Confecção dos pavers com resíduos plásticos}

O procedimento para moldagem e cura de corpos de prova seguiu as instruções da norma NBR-5738/2003. Todos foram conformados em camada única em moldes plásticos de forma prismática com dimensões de 2,0x10,0x20,0cm. Inicialmente, os componentes necessários, para compor a argamassa de concreto, dispostos na Tabela 1 , foram pesados em balança semi-analítica (OHAUS/ARC120) e, na sequência, foram levados à argamassadeira (SOLOCAP), com a finalidade de bater e homogeneizar a massa. A mesma quantidade de argamassa foi distribuída entre as formas prismáticas, as quais foram posteriormente levadas à mesa vibratória (NVI), por um período de 30 segundos, com o intuito de uniformizar a distribuição pelas formas. A retirada destes corpos de prova dos moldes ocorreu após um período de 24 horas e, posteriormente, os mesmos foram submersos em um tanque com água saturada de cal (período de cura), onde ficaram nos tempos de 7, 14 e 28 dias.

\section{Tabela 1. Condições experimentais empregadas na confecção dos corpos de prova.}

\begin{tabular}{cccc}
\hline \multirow{2}{*}{ Materiais } & \multicolumn{3}{c}{ Quantidade de Materiais utilizados $\mathbf{( K g )}$} \\
& Referência & $\mathbf{5 \%}$ & $\mathbf{1 5 \%}$ \\
\hline Areia & 2,00 & 1,90 & 1,70 \\
Brita & 1,00 & 1,00 & 1,00 \\
Cimento & 1,00 & 1,00 & 1,00 \\
Água & 0,50 & 0,50 & 0,50 \\
Resíduo Plástico & - & 0,10 & 0,30 \\
\hline Soma & $\mathbf{4 , 5 0}$ & $\mathbf{4 , 5 0}$ & $\mathbf{4 , 5 0}$ \\
\hline
\end{tabular}

Para cada quantidade percentual adotada(referência, 5 e 15\%), foram confeccionados seis corpos de prova (Figura 2) para cada idade (7, 14 e 28 dias), mais 4 corpos de prova para cada traço, no período de 28 dias, as quais foram moldados para a realização das Análises Físicas exigidas pela NBR-9778/1987. 


\section{Figura 2: Pavers confeccionados com resíduos plásticos. Fonte: Autoria própria (2015).}

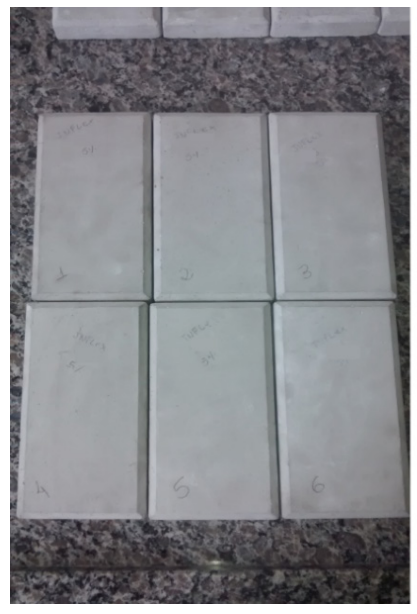

\section{Análises Físicas}

Para a realização das análises físicas, os corpos de prova foram levados, por um período de $24 \mathrm{~h}$, em estufa (DELEO/9) a $100^{\circ} \mathrm{C}$ e, ao retirá-los foi aferida a massa seca. $\mathrm{Na}$ sequência, os mesmos foram imersos em água, pelo mesmo período de tempo e, no término das $24 \mathrm{~h}$, foram obtidas as massas das amostras saturadas e imersas em água, sendo essa última realizada com o auxílio de uma balança hidrostática. As análises físicas realizadas foram: absorção de água por imersão, índice de vazios, massa específica da amostra seca e massa específica da amostra saturada. Sendo cada uma delas calculadas pelas fórmulas:

- Absorção de água por imersão (\%):

Sendo: Msat = Massa da amostra saturada e Ms = Massa da amostra seca;

- Índice de vazios (\%):

Sendo: Msat $=$ Massa da amostra saturada, Ms = Massa da amostra seca e Mi = Massa da amostra imersa em água;

- Massa específica da amostra seca (g/g):

Sendo: Msat $=$ Massa da amostra saturada, Ms = Massa da amostra seca e Mi = Massa da amostra imersa em água;

- Massa específica da amostra saturada (g/g):

Sendo: Msat $=$ Massa da amostra saturada, Ms =Massa da amostra seca e $\mathrm{Mi}=$ Massa da amostra imersa em água; 


\section{Resistência à Compressão}

A determinação da Resistência à Compressão foi realizada seguindo as recomendações da NBR-9780/1987, em prensa hidráulica.

\section{Resultados e Discussões}

\section{Análise Granulométrica:}

\section{Agregados Miúdos (areia e pellets)}

Conforme ABNT/NBR 7211/2005, define-se como agregado miúdo, o agregado cujos grãos passam pela peneira com abertura de malha de $4,75 \mathrm{~mm}$ e ficam retidos na peneira com abertura de malha de 0,15 mm. Assim sendo, tanto a areia quanto os pellets de plásticos aqui analisados são classificados como agregados miúdos.

\section{Areia}

A Tabela 2 apresenta os valores de dois ensaios da massa do material retido, bem como seus respectivos percentuais de material retido e retido acumulado. Em seguida, a Figura 3 mostra a curva granulométrica plotada, com base nos dados apresentados nesta tabela.

\section{Tabela 2. Ensaio de granulometria da areia.}

\begin{tabular}{|c|c|c|c|c|c|c|c|}
\hline \multicolumn{5}{|c|}{ Material de ensaio: Areia } & \multicolumn{3}{|c|}{ Data do ensaio: $30 / 06 / 2015$} \\
\hline \multirow{3}{*}{$\begin{array}{l}\text { Peneiras } \\
(\mathrm{mm})\end{array}$} & \multicolumn{3}{|c|}{ Ensaio 1: massa inicial $500 \mathrm{~g}$} & \multicolumn{3}{|c|}{ Ensaio 2: massa inicial $500 \mathrm{~g}$} & \multirow{3}{*}{$\begin{array}{c}\text { Valores } \\
\text { médios do } \\
\text { percentual do } \\
\text { material retido } \\
\text { acumulado (\%) }\end{array}$} \\
\hline & \multirow{2}{*}{$\begin{array}{l}\text { Massa de } \\
\text { material } \\
\text { retido }(\mathrm{g})\end{array}$} & \multicolumn{2}{|c|}{$\begin{array}{l}\text { Percentual de } \\
\text { material }\end{array}$} & \multirow{2}{*}{$\begin{array}{l}\text { Massa de } \\
\text { material } \\
\text { retido }(g)\end{array}$} & \multicolumn{2}{|c|}{ Percentual de material } & \\
\hline & & $\begin{array}{c}\text { Retido } \\
(\%)\end{array}$ & $\begin{array}{c}\text { Retido } \\
\text { acumulado } \\
(\%)\end{array}$ & & $\begin{array}{c}\text { Retido } \\
(\%)\end{array}$ & $\begin{array}{c}\text { Retido } \\
\text { acumulado } \\
(\%)\end{array}$ & \\
\hline \multicolumn{8}{|l|}{9,5} \\
\hline \multicolumn{8}{|l|}{6,3} \\
\hline 4,75 & 2,3 & 0,46 & 0,46 & 1,2 & 0,24 & 0,24 & 0,35 \\
\hline 2,36 & 5,1 & 1,02 & 1,48 & 4,1 & 0,82 & 1,06 & 1,27 \\
\hline 1,18 & 19,25 & 3,85 & 5,33 & 19,36 & 3,87 & 4,93 & 5,13 \\
\hline 0,6 & 73,8 & 14,76 & 20,09 & 74,4 & 14,88 & 19,81 & 19,95 \\
\hline 0,3 & 342,45 & 68,49 & 88,58 & 344,2 & 68,84 & 88,65 & 88,62 \\
\hline 0,15 & 50,85 & 10,17 & 98,75 & 48,5 & 9,7 & 98,35 & 98,55 \\
\hline Fundo & 6,05 & 1,21 & 99,96 & 8,06 & 1,61 & 99,96 & 99,96 \\
\hline Total & 499,8 & 99,96 & 99,96 & 499,82 & 99,96 & 99,96 & 99,96 \\
\hline
\end{tabular}

Fonte: O Autor (2015) 


\section{Figura 3: Curva granulométrica da areia (Valores médios do percentual retido acumulado).}

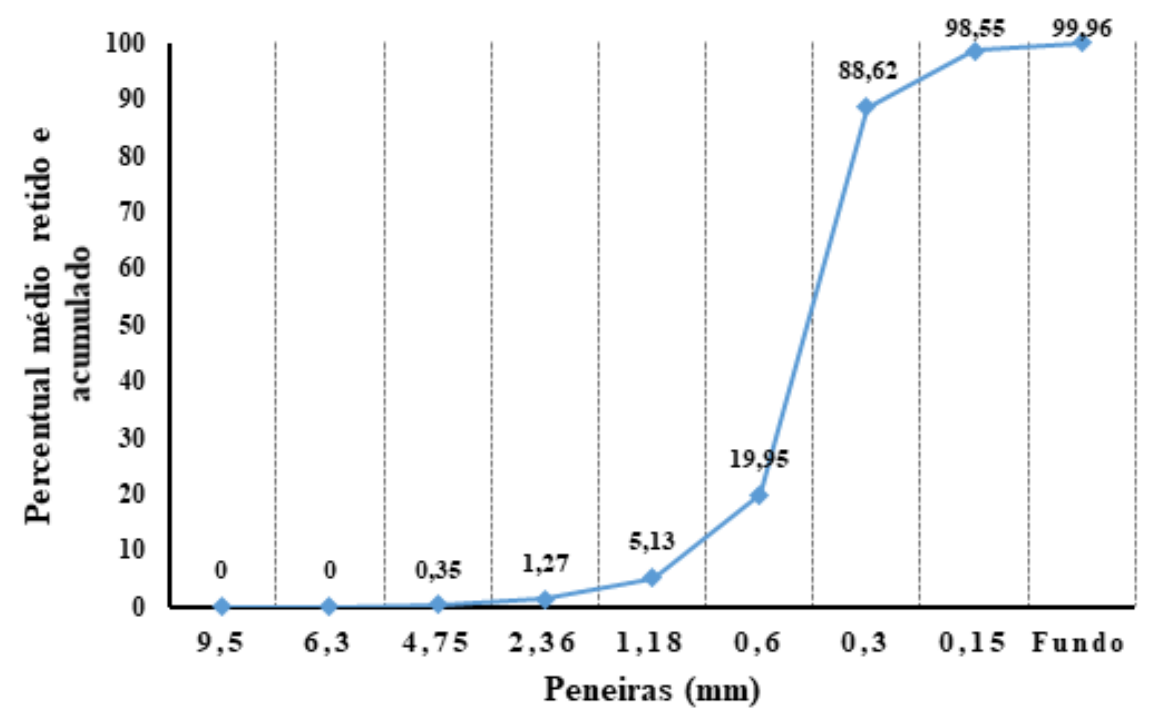

Pode-se observar, com base nos dados dos valores médios do percentual do material retido acumulado apresentados acima, que o material se divide majoritariamente em três faixas granulométricas: a primeira faixa abrange a maioria da amostra, retida na peneira de $0,3 \mathrm{~mm}$ (aproximadamente 68,5\%). A segunda faixa, com maior quantidade de material retido, abrange os grãos retidos na peneira de 0,6 mm (aproximadamente 14,8\%). E por fim, a terceira faixa, com aproximadamente $10,2 \%$ da massa retida na peneira de 0,15 $\mathrm{mm}$. De acordo com Deus et al. (2015), a areia com granulometria variando entre $0,3 \mathrm{~mm}$ e $0,6 \mathrm{~mm}$ é classificada como areia média, abaixo desta medida pode ser considerada areia fina. Assim sendo, como aproximadamente $83 \%$ das partículas aqui estudadas estão na faixa acima citada, pode-se considerar esta areia como média.

\section{Pellets}

De forma análoga ao estudo granulométrico feito anteriormente com a areia, a Tabela 3, apresenta os dados deste ensaio para os Pellets de sacolas plásticas. Após, tem-se, na Figura 4, a curva granulométrica dos Pellets, plotada com base nos dados da Tabela 3. 
Tabela 3. Ensaio de granulometria dos pellets.

\begin{tabular}{|c|c|c|c|c|c|c|c|}
\hline \multicolumn{5}{|c|}{ Material de ensaio: Pellets } & \multicolumn{3}{|c|}{ Data do ensaio: $30 / 06 / 2015$} \\
\hline \multirow{3}{*}{$\underset{\text { (mm) }}{\text { Peneiras }}$} & \multicolumn{3}{|c|}{ Ensaio 1: massa inicial $500 \mathrm{~g}$} & \multicolumn{3}{|c|}{ Ensaio 2: massa inicial $500 \mathrm{~g}$} & \multirow{3}{*}{\begin{tabular}{|c} 
Valores \\
médios do \\
percentual \\
do \\
material \\
retido \\
acumulado \\
$(\%)$
\end{tabular}} \\
\hline & \multirow{2}{*}{$\begin{array}{l}\text { Massa de } \\
\text { material } \\
\text { retido }(\mathrm{g})\end{array}$} & \multicolumn{2}{|c|}{$\begin{array}{c}\text { Percentual de } \\
\text { material }\end{array}$} & \multirow{2}{*}{$\begin{array}{l}\text { Massa de } \\
\text { material } \\
\text { retido (g) }\end{array}$} & \multicolumn{2}{|c|}{$\begin{array}{c}\text { Percentual de } \\
\text { material }\end{array}$} & \\
\hline & & $\begin{array}{c}\text { Retido } \\
\text { (\%) }\end{array}$ & $\begin{array}{c}\text { Retido } \\
\underset{(\%)}{\text { acumulado }}\end{array}$ & & $\begin{array}{c}\text { Retido } \\
\text { (\%) }\end{array}$ & $\begin{array}{c}\text { Retido } \\
\underset{(\%)}{\text { acumulado }}\end{array}$ & \\
\hline \multicolumn{8}{|l|}{9,5} \\
\hline 6,3 & 0,34 & 0,068 & 0,07 & 0,42 & 0,084 & 0,084 & 0,077 \\
\hline 4,75 & 7,35 & 1,47 & 1,54 & 12,65 & 2,53 & 2,61 & 2,08 \\
\hline 2,36 & 486,25 & 97,25 & 98,79 & 473,8 & 94,76 & 97,37 & 98,08 \\
\hline 1,18 & 4,5 & 0,9 & 99,69 & 6,5 & 1,3 & 98,67 & 99,18 \\
\hline 0,6 & 0,8 & 0,16 & 99,85 & 0,95 & 0,19 & 98,86 & 99,86 \\
\hline 0,3 & 0,65 & 0,13 & 99,98 & 0,95 & 0,19 & 99,05 & 99,52 \\
\hline \multicolumn{8}{|l|}{0,15} \\
\hline Fundo & & & 99,98 & & & 99,05 & \\
\hline Total & 499,99 & 99,86 & 99,98 & 495,62 & 99,05 & 99,12 & 99,56 \\
\hline
\end{tabular}

Fonte: O Autor (2015)

\section{Figura 4: Curva granulométrica dos pellets (Valores médios do percentual retido acumulado).}

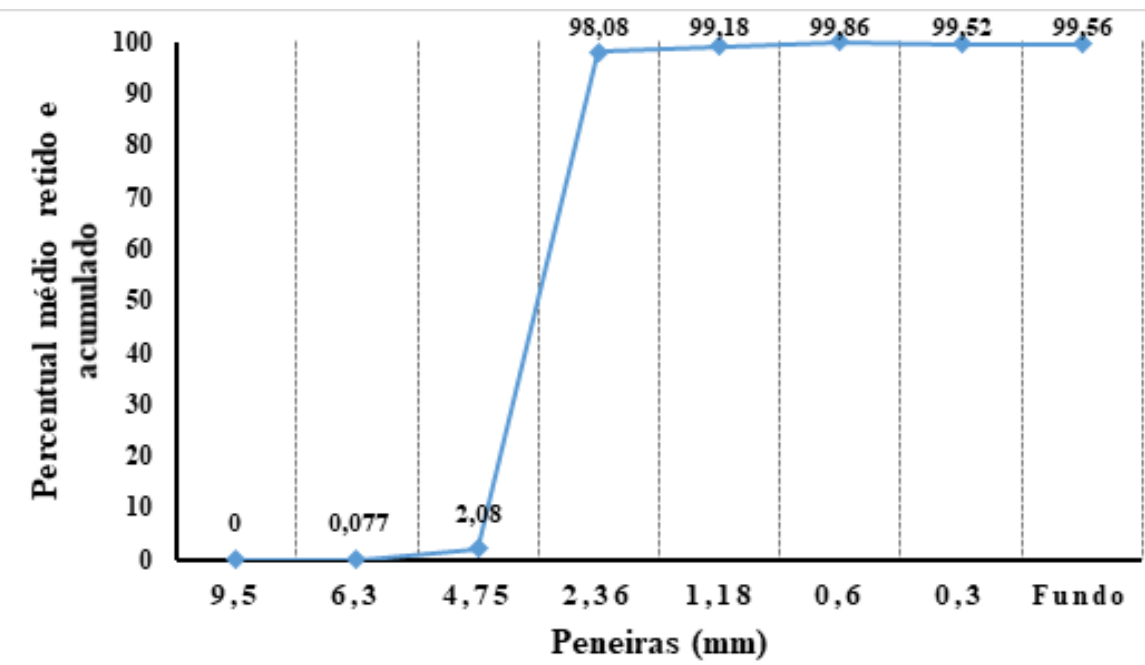

Pode-se observar, com base nos dados apresentados nas tabelas e na curva granulométrica, que o material em questão tem uma granulometria uniforme, apresentando grande porcentagem (aproximadamente 97\%) da amostra retida na peneira de diâmetro 2,36 mm.

Constata-se que a amostra não apresenta porcentuais de material de fundo, bem como a quantidade insignificante de resíduos retidos nas peneiras de 0,6 mm, 0,3 $\mathrm{mm}$ e 0,15 $\mathrm{mm}$. Na peneira de diâmetro $1,18 \mathrm{~mm}$, há uma quantidade maior de resíduos retidos (em torno de $0,90 \%$ ), entretanto, ainda é um percentual muito pequeno se comparado à peneira de 2,36 mm. 


\section{Agregado Graúdo (brita)}

Segundo ABNT/NBR 7211/2005, define-se como agregado graúdo, o agregado cujos grãos passam pela peneira com abertura de malha de $75 \mathrm{~mm}$ e ficam retidos na peneira com abertura de malha de 4,75 mm. Utilizando da mesma metodologia anterior, a Tabela 4 apresenta os resultados para o agregado graúdo aqui empregado. Em seguida, a Figura 5 exibe sua curva granulométrica.

Tabela 4. Ensaio de granulometria do agregado graúdo (brita).

\begin{tabular}{|c|c|c|c|c|c|c|c|}
\hline \multicolumn{5}{|c|}{ Material de ensaio: Brita } & \multicolumn{3}{|c|}{ Data do ensaio: 30/06/2015 } \\
\hline \multirow{3}{*}{$\begin{array}{l}\text { Peneiras } \\
(\mathrm{mm})\end{array}$} & \multicolumn{3}{|c|}{ Ensaio 1: massa inicial $5000 \mathrm{~g}$} & \multicolumn{3}{|c|}{ Ensaio 2: massa inicial $5000 \mathrm{~g}$} & \multirow{3}{*}{$\begin{array}{c}\text { Valores } \\
\text { médios do } \\
\text { percentual } \\
\text { do } \\
\text { material } \\
\text { retido } \\
\text { acumulado } \\
(\%)\end{array}$} \\
\hline & \multirow{2}{*}{$\begin{array}{l}\text { Massa de } \\
\text { material } \\
\text { retido }(\mathrm{g})\end{array}$} & \multicolumn{2}{|c|}{$\begin{array}{c}\text { Percentual de } \\
\text { material }\end{array}$} & \multirow{2}{*}{$\begin{array}{l}\text { Massa de } \\
\text { material } \\
\text { retido }(\mathrm{g})\end{array}$} & \multicolumn{2}{|c|}{$\begin{array}{c}\text { Percentual de } \\
\text { material }\end{array}$} & \\
\hline & & $\underset{\text { (\%) }}{\text { Retido }}$ & $\underset{(\%)}{\text { Retido }}$ & & $\underset{(\%)}{\text { Retido }}$ & 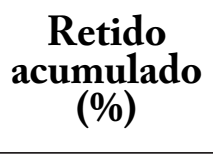 & \\
\hline 9,5 & 41,5 & 0,83 & 0,83 & 36,5 & 0,73 & 0,73 & 0,78 \\
\hline 6,3 & $1.605,5$ & 32,19 & 33,02 & 1.610 & 32,20 & 32,93 & 32,98 \\
\hline 4,75 & $1.290,5$ & 25,81 & 58,83 & 1.085 & 21,70 & 54,63 & 56,73 \\
\hline 2,36 & $1.085,5$ & 21,71 & 80,54 & 1139 & 22,78 & 77,41 & 78,98 \\
\hline 1,18 & 362 & 7,24 & 87,78 & 471 & 9,42 & 86,83 & 87,31 \\
\hline 0,6 & 184 & 3,68 & 91,46 & 227 & 4,54 & 91,37 & 91,42 \\
\hline 0,3 & & & & & & & \\
\hline 0,15 & & & & & & & \\
\hline Fundo & 426,5 & 8,53 & 99,99 & 415 & 8,30 & 99,67 & 99,83 \\
\hline Total & $4.995,5$ & 99,99 & 99,99 & $4.983,5$ & 99,67 & 99,67 & 99,83 \\
\hline
\end{tabular}

Fonte: O Autor (2015)

Figura 5: Curva granulométrica da brita (Valores médios do percentual retido acumulado).

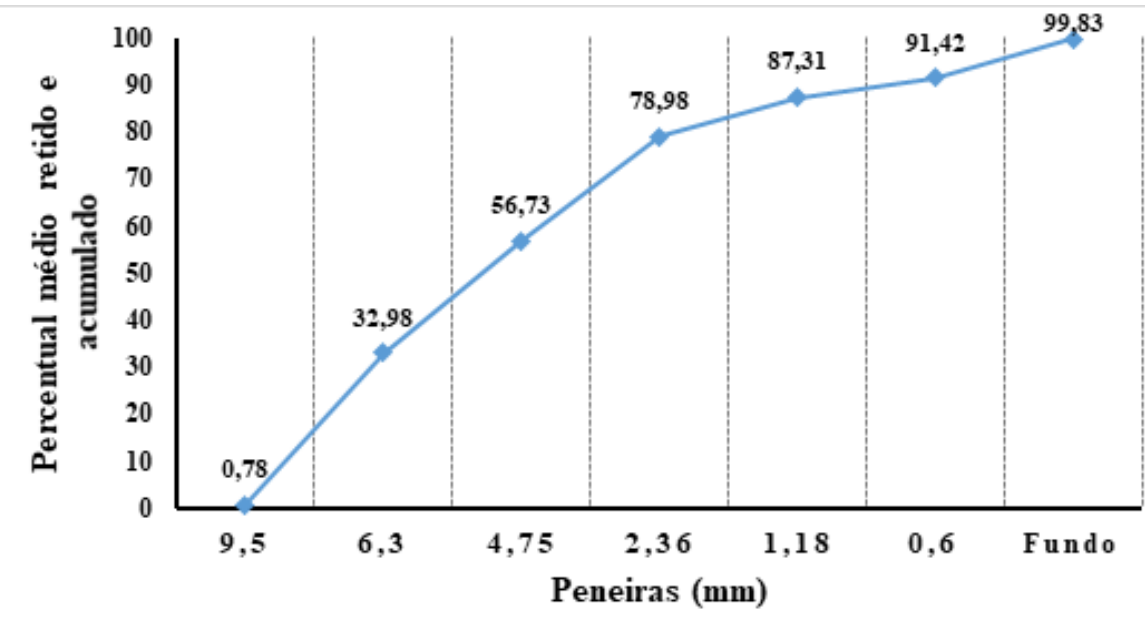

Através da curva granulométrica acima, percebe-se então que a "brita" utilizada é, na verdade, uma mistura do pó de brita, já que, aproximadamente 33\% do material passaram pela peneira de $4,8 \mathrm{~mm}$ e brita zero ou pedrisco (aproximadamente $60 \%$ do material ficou retido entre as peneiras com malhas entre $4,8 \mathrm{~mm}$ e $9,5 \mathrm{~mm}$ ). 
Comparando as respectivas curvas granulométricas para os agregados miúdos, atentase para o fato de que, enquanto a curva granulométrica da areia mostra a maioria dos grãos retidos entre as peneiras com malhas $0,3 \mathrm{~mm}, 0,6 \mathrm{~mm}$ e $0,15 \mathrm{~mm}$, para os pellets, essa retenção ocorreu na peneira com malha 2,36 mm. Já para o agregado graúdo, essa retenção permaneceu majoritariamente entre as peneiras de malhas $6,3 \mathrm{~mm}, 4,75 \mathrm{~mm}$ e 2,36 mm, respectivamente.

Para SILVA et al. (2018), a importância na mistura dos agregados miúdos e graúdos é que ocorre uma redução da interconectividade dos poros no material, o que reduz a absorção de água e o índice de vazios. Assim, as dimensões menores dos agregados no microconcreto, promoveram ganhos, tanto nas propriedades mecânicas, quanto na redução da permeabilidade do concreto.

\section{Módulo de finura e Diâmetro máximo dos agregados}

O módulo de finura de um agregado corresponde ao valor resultante da soma do percentual acumulado nas peneiras de $9,5 \mathrm{~mm}, 4,75 \mathrm{~mm}, 2,36 \mathrm{~mm}, 1,18 \mathrm{~mm}, 0,6 \mathrm{~mm}, 0,3 \mathrm{~mm}$ e $0,15 \mathrm{~mm}$, divididos por 100. Na curva granulométrica de um material, o módulo de finura é representado pela área limitada entre a mesma e o eixo horizontal (integral da curva granulométrica). Assim sendo, o módulo de finura sugere se o agregado é mais grosso ou mais fino, sendo que, quanto maior o módulo, mais grosso é o agregado. O Diâmetro Máximo Corresponde ao número da peneira da série normal, na qual o porcentual acumulado é inferior ou igual a 5\%, desde que esse porcentual seja superior a $5 \%$ na peneira imediatamente abaixo.

Os módulos de finura e o diâmetro máximo característico, respectivos para cada agregado, estão resumidos na Tabela 5 .

\section{Tabela 5. Módulo de finura e Diâmetro máximo característico}

\begin{tabular}{ccc}
\hline Agregado & Modulo de finura & Diâmetro Máximo característico $(\mathbf{m m})$ \\
\hline Areia & 0,99 & 2,36 \\
Pellets & 3,98 & 4,75 \\
Brita & 3,15 & 9,5
\end{tabular}

Fonte: O Autor (2015)

Os resultados demonstram que a areia média em questão é classificada como uma areia muito fina, cujo módulo de finura é 0,99 , com diâmetro máximo de $2,36 \mathrm{~mm}$ e com aproximadamente $1 \%$ em massa nessa faixa granulométrica. Para os pellets tem-se um módulo de finura de 3,98, diâmetro máximo de 4,75 mm e aproximadamente $1,47 \%$ em massa nessa faixa. Por fim, para a brita, tem-se módulo de 3,15, diâmetro máximo de $9,5 \mathrm{~mm}$ e aproximadamente $0,83 \% \mathrm{em}$ massa nessa faixa granulométrica. Os resultados para estes testes já eram esperados, haja vista que os grãos dos resíduos pellets e brita, em geral possuem maior dimensão que os grãos de areia.

Conforme NEVILLE E BROOKS (2010), a boa aderência entre os agregados graúdo e a matriz depende de as partículas serem praticamente de mesmo tamanho, da limpeza, da ausência de pó e da uniformidade do agregado, já o agregado miúdo deve ser um pouco grosso, arredondado e ter granulometria uniforme. $\mathrm{O}$ tamanho e a forma dos agregados influenciam no adensamento de partículas, afetando diretamente o índice de vazios, o qual está ligado com a durabilidade do concreto e também com sua resistência. 
Analisando os gráficos de granulometria para os três agregados, pode-se afirmar que, em relação ao agregado graúdo, esse material, embora possua aproximadamente $60 \%$ de brita considerada zero ou pedrisco, possui também um percentual de aproximadamente $33 \%$ de pó de brita, fato que segundo NEVILLE E BROOKS (2010), poderá comprometer a boa aderência entre os mesmos e a matriz. Em relação aos agregados miúdos, pode-se afirmar que ambos atendem aos requisitos de tamanho e forma, condições necessárias para um bom adensamento de partículas.

\section{Absorção de água por imersão}

A Figura 6 esboça o comportamento dos corpos de prova quanto à absorção de água por imersão. Os mesmos foram submetidos aos testes após o período de cura de 28 dias exigidos pela NBR-9778/1987.

\section{Figura 6: Gráfico de absorção de água por imersão.}

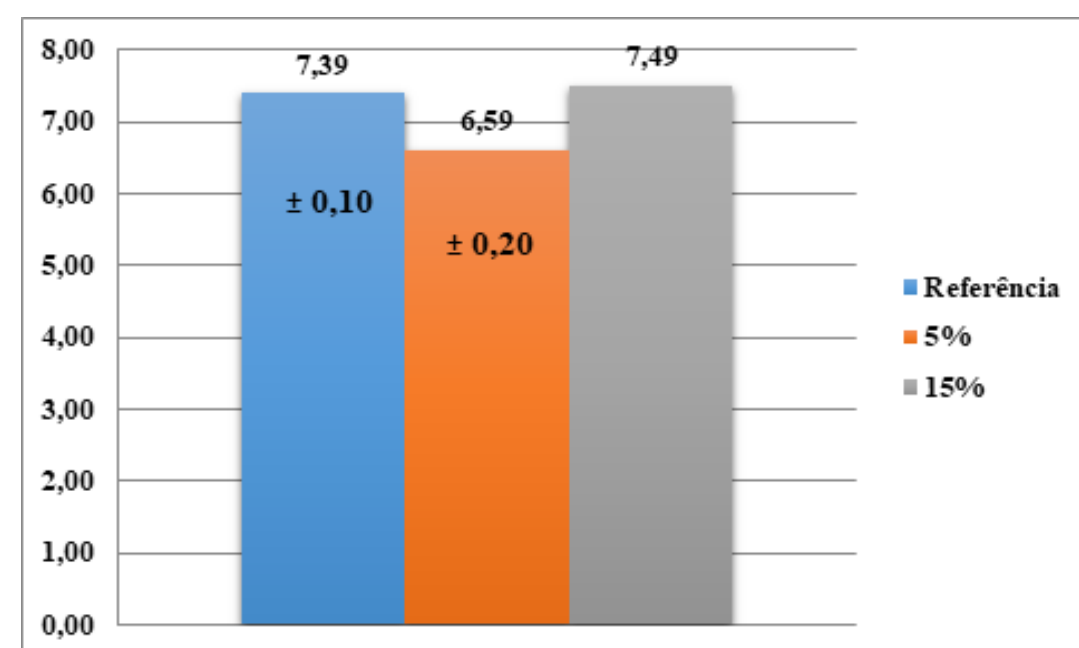

De acordo com a Figura 6, pode-se observar que a absorção de água para a lajota, com substituição de 5\%, apresentou redução de $12,1 \%$ no seu valor se comparado com a referência. Esse comportamento pode ser atribuído à característica dos plásticos em absorver menos água. As lajotas de referência e as de 15\% apresentaram valores com uma divergência de apenas 1,4\%, ou seja, significa que a introdução de resíduos plásticos, na proporção de $15 \%$, pouco contribuiu para o aumento ou redução da absorção de água pelas amostras.

\section{Índice de vazios}

O comportamento do índice de vazios das amostras com e sem substituição pode ser observado na Figura 7. 


\section{Figura 7: Gráfico de Índice de vazios.}

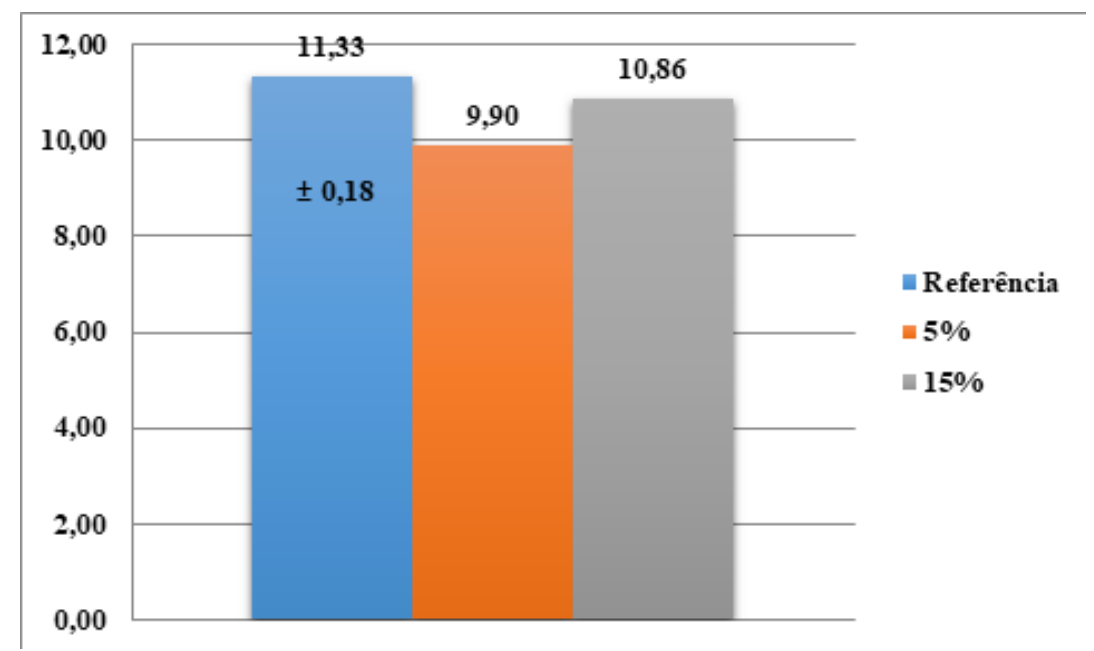

O índice de vazios está diretamente relacionado com a permeabilidade dos materiais e, ao comparar a Figura 6 com a Figura 7, nota-se essa relação ao analisar o índice de vazios das amostras de 5\%, com o baixo índice de absorção de água. Entretanto, os corpos de prova de 15\% apresentaram uma pequena redução no seu índice de vazios, ao passo que apresentou uma maior absorção de água, isto ocorre devido ao tipo de poro presente na amostra, pois existem poros efetivos, que são aqueles que contribuem para o transporte de fluidos e os poros isolados (fechados), os quais não contribuem. Dessa forma, é possível afirmar que, mesmo tendo apresentado maior índice de vazios, as amostras de referência possuem, em sua maioria, poros isolados, os quais não contribuem para a absorção de água.

No ramo da construção civil, a durabilidade do concreto é uma das principais propriedades a ser considerada, pois se trata de uma característica que retrata a sua capacidade de atender ou não a vida útil exigida. A durabilidade depende muito da facilidade com que os fluidos possam ingressar no concreto e se deslocar no seu interior (CARRIJO, 2005). Segundo CAMPITELI (1987), para um concreto de boa qualidade, o índice de vazios, na idade madura, é de $10 \%$ a $15 \%$ e é causado por alguns fatores, dentre eles a água da mistura, porosidade dos agregados, alterações na zona de contato entre a pasta e os agregados, fissuras e deficiências em sua produção. A classificação do concreto, quanto ao seu índice de vazios, pode ser vista na Tabela 16. Desta forma, a redução do índice de vazios, provavelmente causada pela introdução dos resíduos plásticos na mistura, e que proporcionou também a redução da capacidade de absorção de água, apresenta-se como uma vantagem para a durabilidade do concreto. 
Tabela 6. Qualidade do concreto.

\begin{tabular}{cc}
\hline Qualidade do concreto & Índice de vazios (\%) \\
\hline Excelente & 10 a 11 \\
Boa & 11 a 15 \\
Satisfatória & 16 a 18 \\
Medíocre & 19 a 22 \\
Ruim e Muito ruim & 22
\end{tabular}

Fonte: Campiteli, 1987.

\section{Massa específica da amostra seca e saturada}

A Tabela 7 apresenta os resultados dos ensaios das massas específicas das amostras secas e saturadas NBR NM 53 (ABNT, 2003).

Tabela 7. Resultados obtidos das massas específicas das amostras secas e saturadas.

\begin{tabular}{cccc}
\hline \multirow{2}{*}{ Amostra } & \multicolumn{2}{c}{ Ensaio $\left(\mathbf{g} / \mathbf{c m}^{\mathbf{3}}\right)$} & Resultado médio \\
\cline { 2 - 3 } & $\begin{array}{c}\text { amostras } \\
\text { secas }\end{array}$ & $\begin{array}{c}\text { amostras } \\
\text { saturadas }\end{array}$ & \\
\hline Referência & 1,53 & 1,65 & 1,59 \\
$5 \%$ & 1,50 & 1,60 & 1,55 \\
$15 \%$ & 1,45 & 1,56 & 1,51 \\
\hline
\end{tabular}

Fonte: O Autor (2015)

Os resultados obtidos mostram que, tanto para as amostras secas quanto para as saturadas, com a substituição do teor de pellets houve diminuição do resultado médio da massa específica do concreto em relação à referência (redução de 2,52\% no teor de 5\% e de 5,03\% no teor de 15\%). Ou seja, quanto maior o teor substituído, menor a massa específica do concreto.

De acordo com NEVILLE E BROOKS (2010), existem vantagens consideráveis na redução da massa específica do concreto. As principais são a redução da carga permanente e, consequentemente, as cargas totais dos diversos elementos, e a correspondente redução nas dimensões das fundações.

Além disso, com o concreto mais leve, as formas precisarão resistir a uma pressão menor que, no caso do concreto comum e a massa total do material a ser transportado, é reduzida, com consequente aumento da produtividade. Assim, a opção do uso de concreto estrutural fica determinada por considerações econômicas.

\section{Resistência mecânica a compressão}

Os pavers já curados foram submetidos a um processo de capeamento para garantir que suas bases ficassem regularizadas e ocorresse uma homogeneização das forças aplicadas nas superfícies, conforme NBR 12118:2006. Para esta análise, foram utilizados 06 corpos de prova para cada percentual de resíduos plásticos e cada período de cura. A Tabela 8 resume as resistências mecânicas a compressão média para cada traço analisado. 
Tabela 8. Resistências médias de cada traço.

\begin{tabular}{cccc}
\hline & \multicolumn{3}{c}{ Resistência mecânica a compressão (Mpa) } \\
\hline \multirow{2}{*}{ Corpos de prova } & \multicolumn{3}{c}{ Tempo de cura } \\
\cline { 2 - 4 } & $\mathbf{7 ~ d i a s}$ & $\mathbf{1 4}$ dias & $\mathbf{2 8}$ dias \\
\hline Referência & 27,57 & 29,27 & 29,79 \\
5\% de substituição & 37,51 & 37,99 & 34,58 \\
15\% de substituição & 34,67 & 32,83 & 34,15 \\
\hline Fonte: O Autor (2015) & &
\end{tabular}

Analisando a Tabela 8, verifica-se que em termos percentuais, tanto os corpos de prova com 5\% como com 15\% de substituição, para um período de cura de 07 dias, apresentam um aumento em suas respectivas resistências mecânicas, de aproximadamente 36\% e 25\% em analogia à resistência mecânica que o concreto referência. Já param o período de cura de 14 dias, tem-se uma melhora na resistência de $29,8 \%$ para a substituição de $5 \%$ e de $12,2 \%$ para os corpos de $15 \%$, também em relação ao concreto referência. Salienta-se que os tempos de cura de 07 e 14 dias foram realizados apenas a título de comparação, já que, segundo a ABNT NBR 9781, o tempo de cura exigido para realização dos testes é o de 28 dias.

Para os corpos de prova com 28 dias de cura, percebe-se através da Tabela 8 pavers com $5 \%$ de substituição e os de 15\%, apresentaram, respectivamente, um aumento de 16,1\% e 14,6\% em relação à resistência mecânica à compressão dos pavers de referência.

Segundo GONZÁLES (1990), polímeros adicionados a concretos convencionais podem trazer benefícios, pois apresentam propriedades como adesão, resistências química e física, bem como a redução considerável do índice de vazios. Alguns autores afirmam que a relação entre índice de vazios e resistência mecânica é inversamente proporcional, pois uma menor quantidade de poros impede a infiltração de grandes quantidades de fluidos que podem comprometer a qualidade das peças.

A ASSOCIAÇÃO BRASILEIRA DE CIMENTO PORTLAND (2014) afirma que a resistência da pasta, a qual é responsável por envolver os agregados e por preencher os vazios, é o principal fator de influência na resistência à compressão, de maneira que, quanto menor for a relação água/cimento, mais resistentes serão as estruturas. Dessa forma, é possível afirmar que as introduções dos resíduos plásticos melhoraram a interação água/cimento, provocando um aumento significativo na resistência do material. Assim sendo, de acordo com a Tabela 8, o concreto obtido com adição de resíduos plásticos é caracterizado como de excelente qualidade em relação ao seu índice de vazios.

\section{Tensão x Deformação}

Conforme HIBBELER (2000), uma característica importante quando se trata do concreto, é a sua elasticidade, ou seja, a propriedade de o corpo de prova sofrer deformações, quando submetido a uma força, e retornar parcial ou totalmente à forma original. Nas Figuras 8, 9 e 10, tem-se os gráficos de Tensão x Deformação dos corpos de prova de 28 dias para cada traço estudado. 
Figura 8: Gráfico de tensão x deslocamento dos corpos de referência

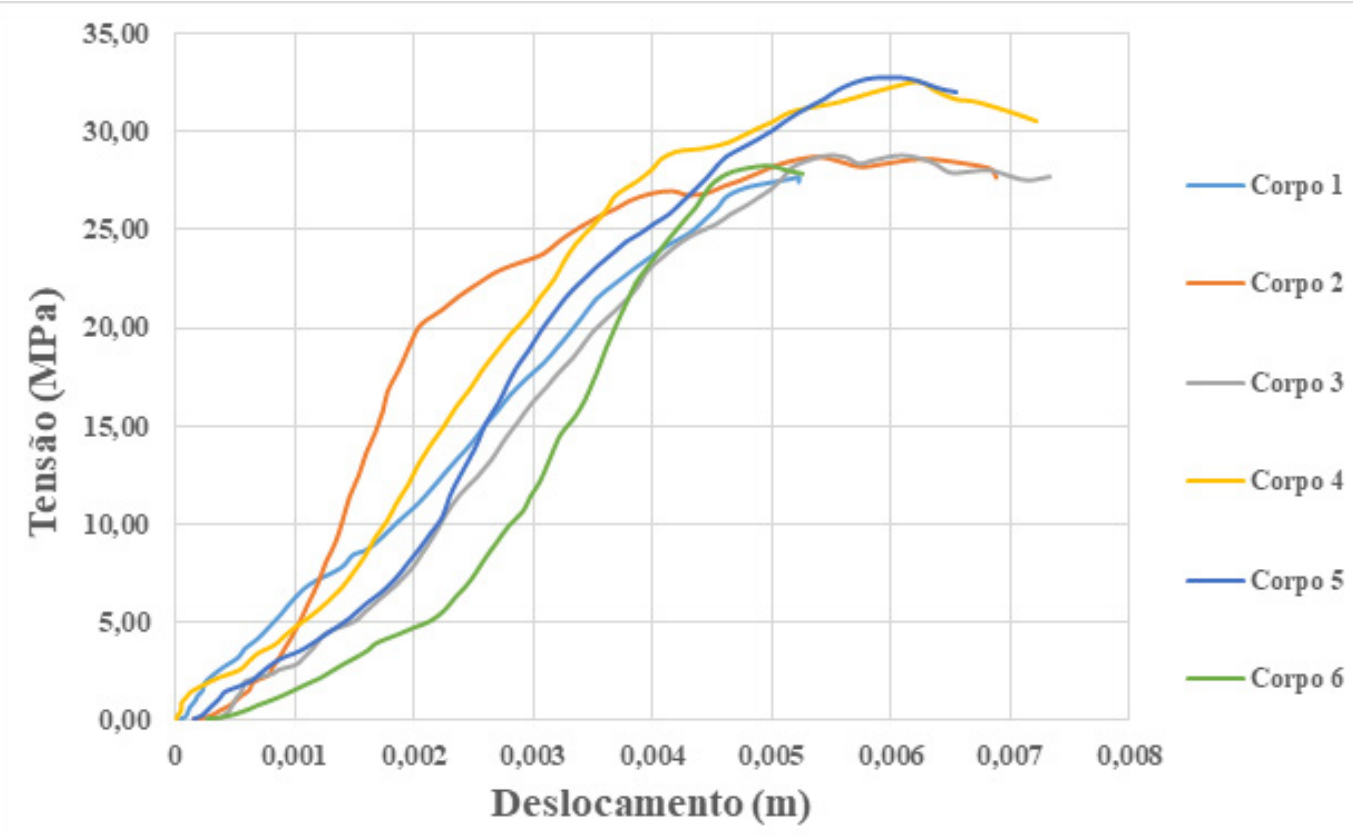

Figura 9: Gráfico de tensão X deslocamento dos corpos de $5 \%$.

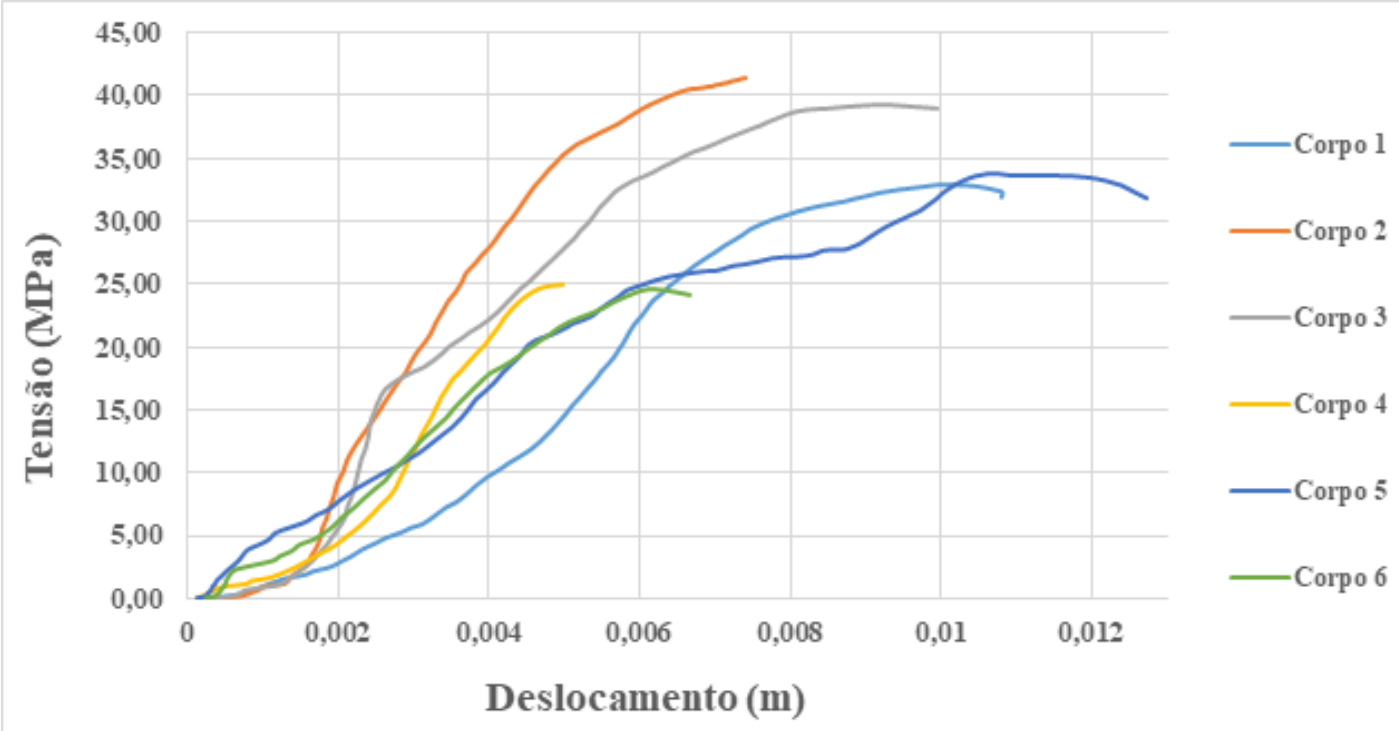




\section{Figura 10: Gráfico de tensão X deslocamento dos corpos de $15 \%$.}

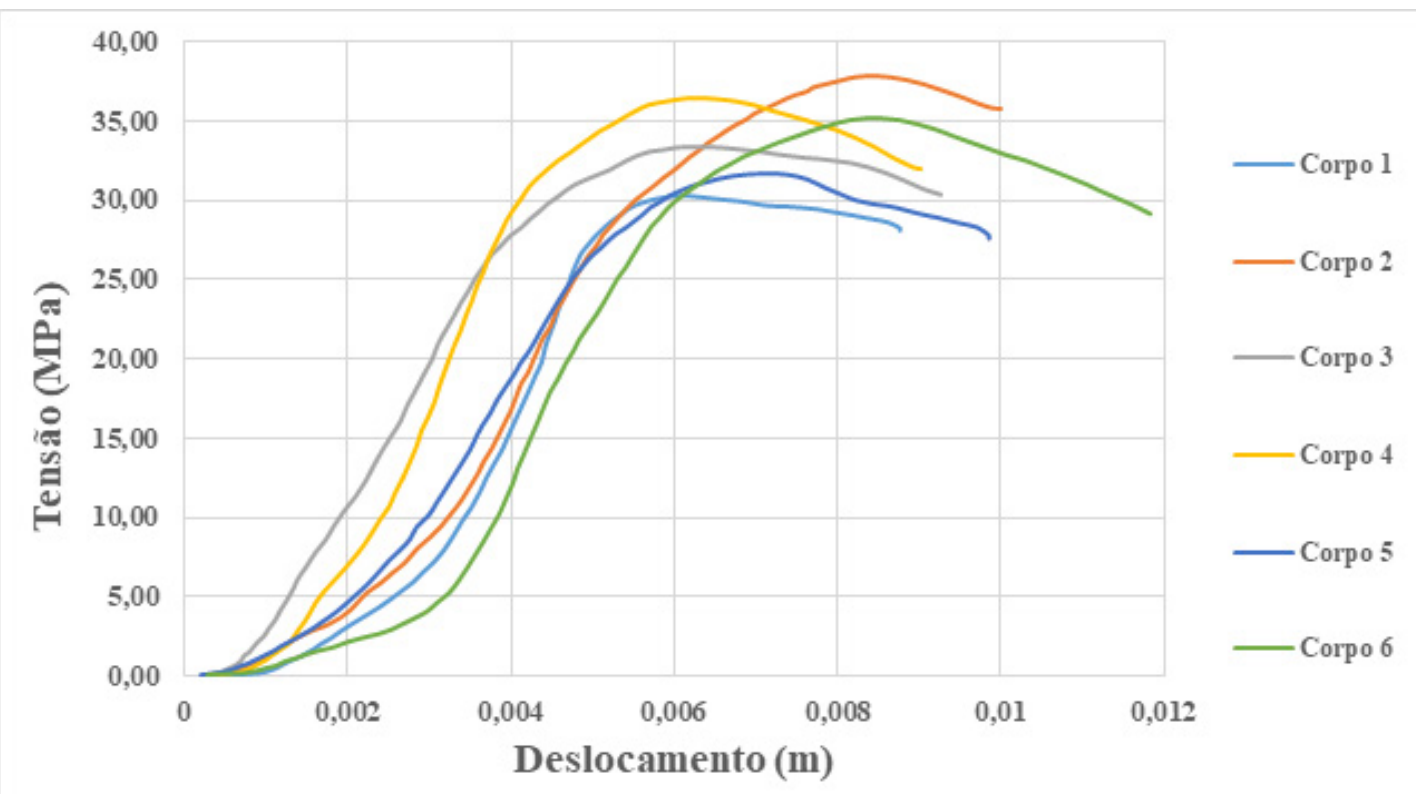

A partir dos gráficos acima, a Tabela 9 exibe os valores médios da resistência pela deformação dos conjuntos de corpos estudados.

\section{Tabela 9. Deformação dos corpos.}

\begin{tabular}{ccc}
\hline Traço & Pressão $(\mathbf{M p a})$ & Deformação $(\mathbf{m})$ \\
\hline Referência & 29,79 & 0,004 \\
$5 \%$ & 34,58 & 0,006 \\
$15 \%$ & 34,15 & 0,005 \\
\hline
\end{tabular}

Fonte: O Autor (2015)

O concreto endurecido é um material que pode ser considerado como pseudo-sólido, pois contém esqueleto sólido, água e ar. Estes dois últimos componentes respondem por parcelas importantes de suas propriedades, nas quais estão incluídas as deformações sob cargas (SANTOS et al., 2013).

A partir da análise dos resultados, nota-se uma deformação um pouco maior dos traços de 5 e 15\% se comparado às amostras de referência, o que provavelmente ocorreu devido a presença dos materiais plásticos, pois, de acordo com BATTAGIN (2008) a deformação elástica do concreto depende fundamentalmente da sua composição, especialmente dos agregados. Assim, ao se adicionar um material mais flexível, altera-se a propriedade elástica do conjunto como um todo, pois os agregados influenciam em outras propriedades, como por exemplo a porosidade, àqual está ligada também com a resistência mecânica do material.

$\mathrm{O}$ aumento da elasticidade apresenta-se como uma vantagem, pois materiais mais flexíveis absorvem maior quantidade de energia antes da sua quebra ou ruptura. 


\section{Considerações Finais}

Esta pesquisa teve como objetivo avaliar as propriedades mecânicas e físicas de pavers incorporados com resíduos plásticos oriundos da indústria de embalagens e, dessa forma, verificar a viabilidade de utilizar este novo material no ramo da construção civil.

Para os corpos de prova com substituição de 5\%, verifica-se uma maior resistência mecânica (34,58 MPa), menor índice de vazios e menor absorção de água. Os pavers com 15\% de resíduos incorporados também apresentaram melhora na resistência $(34,15 \mathrm{MPa})$ se comparado ao concreto referência $(29,79 \mathrm{MPa})$; o índice de vazios também se apresentou inferior, porém, a absorção de água foi 1,4\% maior, considerado um valor baixo, o qual não afetará o desempenho do material. Ou seja, ambos os pavers são indicados para pavimentação de áreas externas como calçamentos de parques, residências e praças. $\mathrm{O}$ emprego dos polímeros ainda proporcionou uma alteração na elasticidade do concreto.

Além de ter contribuído para a melhora das propriedades do material, a inserção de resíduos plásticos no concreto traz benefícios ambientais, pois se forem descartados incorretamente eles degradam os recursos naturais, como rios, lagos, córregos, águas subterrâneas e o solo, e mesmo que fossem destinados a aterros, o tempo que eles levam para se degradar completamente acabaria comprometendo a vida útil destes locais.

Outro benefício a ser destacado é quanto à substituição da areia, por se tratar do agregado necessário em maior quantidade. Em produções de grande escala, o uso de resíduos plásticos permitiria uma redução considerável na sua utilização, o que é bom, tanto economicamente, quanto ambientalmente, pois reduziria os problemas provocados pelo processo de extração.

\section{Referências Bibliográficas}

ALWAELI, M. Radiation Physics and Chemistry. Application of granulated lead-zinc slag in concrete as an opportunity to save natural resources, v. 83, p. 54-60, 2013.

ASSOCIAÇÃO BRASILEIRA DE CIMENTO PORTLAND. Guia básico de utilização do cimento portland. 7. ed. São Paulo: [s.n.], 2002.

Concreto - Relação água/cimento. Disponível em: http://www. comunidadedaconstrucao.com.br/upload/ativos/75/anexo/2relac.pdf. Acesso em: 21/07/2015.

. Guia básico de utilização do cimento portland. 7. ed. São Paulo: [s.n.].

ASSOCIAÇÃO BRASILEIRA DE NORMAS TÉCNICAS. NBR 5738: Concreto Procedimento para moldagem e cura de corpos-de-prova. Rio de Janeiro: ABNT, 2003.

NBR 9778: Argamassa e concreto endurecidos - Determinação da absorção de água por imersão - Índice de vazios e massa específica. Rio de Janeiro: ABNT, 1987.

.NBR 9780: Peças de concreto para pavimentação Determinação da Resistência a Compressão. Rio de Janeiro: ABNT, 1987. 
. NBR 9781: Peças de concreto para pavimentação: Especificação e métodos de ensaio. Rio de Janeiro: ABNT, 2013.

NBR NM 248: Agregados - determinação da composição granulométrica. Rio de Janeiro: ABNT, 2003.

.NBR 7211: Agregados para concreto - especificação. Rio de Janeiro: ABNT,2005.

NBR NM 53: Agregado graúdo - Determinação da massa específica, massa específica aparente e absorção de água. Rio de Janeiro: ABNT, 2003.

NBR 12118: Blocos de concreto vazado simples para alvenaria - Métodos de ensaio. Rio de Janeiro: ABNT, 2013.

BATTAGIN, I. L. S. Módulo de Elasticidade do Concreto Normalização, fatores de influência e interface com o pré-moldado. Disponível em: <http://www.abcic.org.br/ Concrete_show_2008/palestras/Ines_Battagin.pdf $>$.Acesso em: 15/08/2015

BRASIL. Conselho Nacional do Meio Ambiente. Resolução no 313, de 29 de Outubro 2002. Dispõe sobre o Inventário Nacional de Resíduos Sólidos Industriais. Diário Oficial [da] Republica Federativa do Brasil , Brasília, DF , 22 nov. 2002.

BRASIL. Lei n. 12.305, de 2 de agosto de 2010. Institui a Política Nacional de Resíduos Sólidos; altera a Lei no 9.605, de 12 de fevereiro de 1998; e dá outras providências. Disponível em: < http://www.mma.gov.br/port/conama/legiabre.cfm?codlegi=636>. Acesso em: $19 / 04 / 2015$.

BEZERRA, F. A. et al. Polímeros. Pirólise catalítica do PEBD usando como catalisador a vermiculita modificada, v. 26, p. 55-59, 2016.

CAMPITELI. Porosidade do concreto. Companhia de cimento Portland Itaú, 1987.

CÂNDIDO, C. V. L. et al. Plano de Gerenciamento Integrado de Resíduos Plásticos: PGIRP. Belo Horizonte: Fundação Israel Pinheiro, 2009.

CANGEMI,J. M. et al.Química Nova na Escola. Biodegradação: uma alternativa para minimizar os impactos decorrentes dos resíduos plásticos , n. 22, p. 17-21, 2005.

CARRIJO, P. M. Análise da influência da massa específica de agregados graúdos provenientes de resíduos de construção e demolição no desempenho mecânico do concreto. São Paulo: Universidade de São Paulo, 2005.

DEUS, F. P. et al. Pesq. Agropec. Bras. Eficiência de filtros de areia pressurizados na remoção de diferentes tamanhos de partículas da água de irrigação, v.50, n. 10, p. 939948, 2015. 
FERRARI, A. K. Influência do resíduo de PVC moído como substituto parcial do agregado miúdo no concreto dosado para peças de pavimento intertravado. Santa Catarina: Universidade do Estado de Santa Catarina, 2017.

GOMES, P. C. C. et al. Ambiente Construído. Obtenção de blocos de concreto com utilização de resíduos reciclados da própria fabricação dos blocos, v.17, n. 3, p. 367380, 2017.

GONZÁLES, B. Rev. Téc. Ing. Univ. Zulia. Caracterizacion de concretos de polimeros usados en la construccion, v. 13, n. 1, p. 35-43, 1990.

HIBBELER, R. C. Resistência dos Materiais, Terceira Edição, Livros Técnicos e Científicos Editora, Rio de Janeiro, 2000.

ISAIA, G. C. et al. Ambiente Construído. Viabilidade do emprego de cinza de casca de arroz natural em concreto estrutural (parte II): durabilidade, v.17, n.2, p.233-252, 2017.

MATTAR, D. C.; VIANA, E. Rev. Elet. em Gestão, Educação e Tecnologia Ambiental. Utilização de resíduos poliméricos da indústria de reciclagem de plástico em blocos de concreto, v. 8, n. 8 , p. 1722-1733, 2012.

NEVILLE, A.M.; BROOKS,J.J. Tecnologia do concreto. 2. ed. Porto Alegre: Bookman, 2010. v. 1.

OLIVEIRA, M. ClARA B. R. Gestão de Resíduos Plásticos Pós-Consumo: Perspectivas para a reciclagem no Brasil. Rio de Janeiro: Universidade Federal do Rio de Janeiro, 2012.

PIATTI,T.M. Plásticos: características, usos, produções e impactos ambientais, Editora da Universidade Federal de Alagoas, Maceió, 2005.

PIETROBELLI, E. R. Estudo de viabilidade do PET reciclado em concreto sob aspecto da resistência a compressão. Chapecó: Universidade Comunitária da região de Chapecó - UNOCHAPECÓ, 2010.

RIBEIRO, U. G.; VASCONSELOS, L. P. Revista Matéria. Estudo de propriedades térmicas e mecânicas de compósitos cimentícios produzidos com resíduos da indústria madeireira de Porto Velho, v.23, n.4, 2018.

ROYER, B.; ASSUNÇÃO, R.M. N.; RODRIGUES, G. Polímeros: Ciência e Tecnologia. Efeito da Aplicação do Poliestireno Sulfonado (PSSNa) como Aditivo em Argamassas e Concretos de Cimento Portland CPV32, 1. v. 15, p. 63-67, 2005. 
SANTOS, A.M., CABRAL, L. M. C., MONTEIRO, E. B., HELENE, P. R. L.Analise do módulo de elasticidade estático e dinâmico para diferentes dosagens de concreto. Revista IBRACON, 2013.

SILVA, A. C. et al. Revista Matéria. Microconcreto de alto desempenho: propriedades e comportamento de pilar à flexão normal composta, v.23, n.3, 2018.

SILVA, E. J. et al. Revista Ambiência. Análise técnica para o reaproveitamento da fibra de coco na construção civil, v.11, n.3, p.669-683, 2015.

SILVA, E. J. et al. Revista Matéria. Compósito cimentício com elevado teor de fibra de coco tratada: propriedades físicas e durabilidade, v.23, n.3, 2018.

SILVA, T. D. et al. Revista Matéria. Uso de granulado de borracha em substituição parcial ao agregado miúdo na produção de tijolos ecológicos, v.22, n.4, 2017.

SOUZA, C. C. et al. Rev. Eng. Constr. Civil. Estudo das propriedades mecânicas de compósitos obtidos através da incorporação do PET moído em microconcreto, v.2, n.1,p. 29-38, 2015.

SOUZA, M. F. et al. Revista Matéria. Resistência à compressão e viabilidade econômica de blocos de concreto dosado com resíduos de tijolos cerâmicos, v.23, n.3, 2018.

TAFAREL, N. F. et al. Revista Matéria. Avaliação das propriedades do concreto devido à incorporação de lodo de estação de tratamento de água, v.21, n.4, p.974-986, 2016.

VIEIRA, G. V., REZENDE, E. N. Revista do Direito Público. Mineiração de areia e meio ambiente: é possível harmonizar?, v. 11, n. 3, p. 181-212, 2015. 